\title{
Harnessing choice architecture to improve medical care
}

\author{
Donald A Redelmeier (D), Mian-Mian Kao
}

Department of Medicine, University of Toronto, Toronto, Ontario, Canada

\section{Correspondence to} Dr Donald A Redelmeier, University of Toronto, Toronto, ON M4N 1J5, Canada; dar@ices.on.ca

Accepted 25 November 2020 Published Online First

15 January 2021

\section{SLinked}

- http://dx.doi.org/10.1136/ bmjqs-2020-011801

Check for updates

(c) Author(s) (or their employer(s)) 2021. No commercial re-use. See rights and permissions. Published by BMJ.

To cite: Redelmeier DA Kao M-M. BMJ Qual Saf 2021;30:353-355.

\section{INTRODUCTION}

People live busy complex lives where most decisions need to be made quickly. As a consequence, people tend to prefer simple rather than expanded choice sets, easy alternatives that require no complex tradeoffs and benign options that avoid major moral quandaries. Choice architecture is defined formally as the behavioural science examining how the layout, sequencing and range of available options can influence decisions. The Google search engine, for example, is a familiar illustration of refined choice architecture where its spartan user interface tries to avoid overloading individuals, provoking deep thought or maximising information. The core assumption is that people want to feel gently guided and not overwhelmed. The intriguing insight is that many unrecognised features of choice architecture can influence decisions.

In this issue of the journal, Hart et al explore physicians' knowledge of choice architecture in medical care. ${ }^{1}$ The investigators focus on eight principles related to decision science including how first impressions are weighted heavily, defaults matter, people are risk averse toward gains, multiple options increase status quo bias and social norms have abounding influence. The main finding is that over one-third of basic questions on these principles were answered incorrectly by medical residents. An important added finding is that the majority of medical residents endorsed the relevance of choice architecture for clinical practice. Together, this careful and thorough study identifies a shortfall in physicians' understanding of decision science and an opportunity for improving medical education beyond correcting errors in diagnostic reasoning.

The study by Hart et al joins a larger body of basic science examining how choice architecture can be important and readily modified outside of medicine. A classic example is retirement savings plans where changing the default to automatic enrolment can lead to a large increase in retirement savings plan participation rates $(49 \%$ vs $86 \%, \mathrm{p}<0.001) .{ }^{23}$ Another example involves providing a prefilled application to underprivileged high school students can lead to an increase in college enrolment (34\% vs $42 \%$, $\mathrm{p}<0.05) .^{4}$ One recent review suggests changes in choice architecture can also be more cost-effective than traditional policy interventions in social domains. ${ }^{5}$ The main limitation of choice architecture is that this scientific paradigm is not a falsifiable idea since any failure might be blamed on poor implementation. ${ }^{6}$

A limitation of the study by Hart et $a l$ is the analysis only explored a subset of important choice architecture tactics that could make clinicians more effective (table 1). Interventions based on optimising salience, appealing to social norms and preserving ego may be distinctly relevant given a physician's personal knowledge of the patient. Gradual persuasion could also have substantial potential since clinical practice involves following the same patient over time, thereby allowing future choices to be primed and also steered by past choices. In contrast, selecting the right messenger, providing incentives, enhancing attractiveness and switching defaults are interventions typically beyond a clinician's control. ${ }^{7}$ These tactics (the bricks-and-mortar for modifying choice architecture) are not exhaustive and Hart et al have tested only a subset.

Modifications in choice architecture differ from quality improvement initiatives that remove options from clinicians. Automatic stop dates for antibiotics, policies for discontinuing Foley catheters, reductions in drug formularies and many other successful examples of quality 
Table 1 MINDSPACE approach to pragmatic tactics in choice architecture*

\begin{tabular}{|c|c|c|c|}
\hline Tactict & Definition & Strategy for designer & Sentiment for user \\
\hline Messenger & Messages need a credible messenger. & Identify a trusted person to endorse recommendation. & 'This source seems smart and believable.' \\
\hline Incentivesł & Perceived gains and losses drive behaviour. & Assess direct consequences from user's viewpoint. & 'The idea helps me and lessens my problems.' \\
\hline Norms§ & Social norms influence mundane choices. & Selectively appeal to general popularity. & 'My peers accept it so I will do the same.' \\
\hline Defaults & Inaction leads to accepting standard options. & Design positive responses for those who are passive. & 'This seems reasonable and I will just agree.' \\
\hline Salience** & Personal relevance helps motivate people. & Consider the distinct perspective of the user. & 'This sensible suggestion matters to me.' \\
\hline Primingt† & Changing behaviour is a gradual process. & Start in advance giving people time to adjust & 'I heard this earlier and am prepared to act.' \\
\hline Attractive ‡¥ & Aesthetics are a compelling first impression. & Craft the recommendation with simple elegance. & 'This seems pleasant rather than annoying.' \\
\hline Consistency§§ & Past precedents help resolve new tasks. & Show concordance with prior choices. & 'My past actions imply an obvious choice now.' \\
\hline Ego & Self-identity needs comforting & Allow people to gain more self-esteem. & 'I now feel better about myself.' \\
\hline
\end{tabular}

*Adapted from the Institute for Government in the UK available at https://www.instituteforgovernment.org.uk/publications/mindspace.

†Tactic denotes practice rather than theory of choice architecture.

\#Includes framing effect listed by Hart et al.

$\S$ Called social norms listed by Hart et al.

-Connected to default effect and multiple alternatives bias listed by Hart et al.

** Includes relative risk bias listed by Hart et al.

††Similar to anchoring bias listed by Hart et al.

$\ddagger \ddagger$ Includes compromise effect listed by Hart et al.

$\S \S$ Similar to habit formation listed by Hart et al.

improvement work mostly by eliminating options deemed inappropriate. ${ }^{8-11}$ Conversely, initiatives such as adding a surgical checklist or other quality interventions that increase clinician workload tend to be less reliable. ${ }^{13}$ Changes in choice architecture neither subtract nor add a distinct burden onto clinicians; instead, their goal is to guide choice without a constraining function (eg, spell-checking software that offers corrections when writing a medical note). This means changes in choice architecture require less institutional clout and create less stakeholder backlash.

Many other elements of choice architecture coincide with standard quality improvement. This includes emphasising the value of giving feedback (eg, seethrough drip chambers to show intravenous infusion rates), anticipating error (eg, automatic double checks before initiating blood product infusions) and clear process mappings (eg, cardiopulmonary resuscitation algorithms for following resuscitation guidelines). Choice architecture sometimes highlights the disproportionate effect of small salient positive incentives (eg, a slice of pizza offered to a hungry medical student). Choice architecture also strongly emphasises the importance of defaults (eg, distinguishing opt-in from opt-out organ donation programmes) and structured choices (eg, organised order sets for inpatients admitted for heart failure). Good choice architecture rarely conflicts with good quality improvement. ${ }^{14}$

A recent advance in choice architecture involves clean-up campaigns against sludge, defined as barriers that discourage people from doing the right thing. ${ }^{15}$ A clear example of sludge arises in corporations that make it easy to enrol in a subscription service and difficult to cancel the subscription later. The typical features of sludge are awkward obstacles that burden the customer. The thoughtful identification and elimination of sludge can be a remarkably effective way to advance decisions and prosocial behaviour by changing the choice environment (eg, automated telephone answering systems for patients to refill prescriptions). Of course, sometimes sludge is not an unintentional remnant structure that can be readily modified but a deliberate commercial tactic to stop people acting in their own best interests.

An important debate around choice architecture involves preserving patient autonomy, avoiding coercion and allowing freedom. At one extreme, a choice architect might become tantamount to a paternalistic authority infringing on patient liberty or acting maliciously. ${ }^{16}$ At the other extreme, a choice architect may be relegated to a subordinate position, constrained to featherweight interventions and limited to offering trivial changes to patient health. ${ }^{17}$ Each society will have its own values when determining the correct balance between freedom and safety, thereby implying that changes in choice architecture may be more acceptable in some regions than others. Inevitably, this leads to inconsistent clinical implementation of choice architecture despite medical science being portrayed as universal regardless of situation.

The future is likely to provide more opportunities for improved choice architecture that contribute to quality improvement and patient safety in medicine. One framework for conceiving such opportunities is the FEAST mnemonic adapted from the Behavioural Insights Team in the UK (table 2). ${ }^{18}$ The elements are Fun (motivate all stakeholders), Easy (reduce hassle factors), Attractive (design to attract attention), Social (encourage people to commit to others) and Timely (prompt people when they are likely most receptive). These concepts (the vision and blueprint of choice architecture) are now at the frontier for patient safety and quality improvement science. Some of these concepts have been implicitly understood in commercial industries for decades. ${ }^{19}$ The study by Hart et al suggests clinicians are hungry for this FEAST. 
Table 2 FEAST approach to design theory for choice architecture*

\begin{tabular}{llll}
\hline Concept† & Definition & Sentiment for designer & Sentiment for user \\
\hline Fun & Emotionally gratifying to participants. & 'I enjoy working on this project.' & 'I really like this well-crafted offering.' \\
\hline Easy & Simple action requiring little effort or thinking. & 'The intended solution is elegant and sublime.' & 'This is a "no-brainer" and straightforward for me.' \\
Attractive & Inherently pleasant appearance. & 'The intervention looks good with instant appeal.' & 'The options are nice to see and appreciated.' \\
Social & Interactive commitment with other people. & 'The experience engages real human contact.' & 'I felt recognized and welcomed.' \\
Timely & Engaging at a convenient moment. & 'The task focuses attention at the right instant.' & 'The task was timely rather than distracting.' \\
\hline
\end{tabular}

*Adapted from the Behavioural Insights Team in the UK.

tConcept denotes theory rather than practice of choice architecture.

Contributors Both authors contributed to the design, analysis and interpretation of the findings. The first author (DAR) wrote the first draft. Both authors approved the final submitted version.

Funding This study was funded by the Canada Research Chair in Medical Decision Science.

Competing interests None declared.

Patient consent for publication Not required.

Provenance and peer review Commissioned; internally peer reviewed.

\section{ORCID iD}

Donald A Redelmeier http://orcid.org/0000-0003-4147-3544

\section{REFERENCES}

1 Hart J, Yadav K, Szymanski S. Choice architecture in physician-patient communication: a mixed-methods assessment of physicians' competency. BMJ Qual Saf 2021;30:362-71.

2 Madrian BC, Shea DF. The power of suggestion: inertia in 401(k) participation and savings behavior. Q J Econ 2001;116:1149-87.

3 Chetty R, Friedman JN, Leth-Petersen S, et al. Active vs. passive decisions and Crowd-Out in retirement savings accounts: evidence from Denmark *. Q J Econ 2014;129:1141-219.

4 Bettinger EP, Long BT, Oreopoulos P, et al. The role of application assistance and information in college decisions: Results from the H\&R Block FAFSA experiment. Q J Econ 2012;127:1205-42.

5 Benartzi S, Beshears J, Milkman KL, et al. Should governments invest more in Nudging? Psychol Sci 2017;28:1041-55.

6 Susser M. The logic of Sir Karl Popper and the practice of epidemiology. Am J Epidemiol 1986;124:711-8.

7 Dolan P, Hallsworth M, Halpern D, et al. Influencing behaviour: the mindspace way. J Econ Psychol 2012;33:264-77.
8 Leis JA. Advancing infection prevention and antimicrobial stewardship through improvement science. BMJ Qual Saf 2018;27:163-5.

9 Leis JA, Corpus C, Rahmani A, et al. Medical directive for urinary catheter removal by nurses on general medical wards. JAMA Intern Med 2016;176:113-5.

10 Alldred DP, Standage C, Fletcher O, et al. The influence of formulation and medicine delivery system on medication administration errors in care homes for older people. BMJ Qual Saf 2011;20:397-401.

11 Simon GE, Psaty BM, Hrachovec JB, et al. Principles for evidence-based drug formulary policy. J Gen Intern Med 2005;20:964-8.

12 Urbach DR, Dimick JB, Haynes AB, et al. Is who's surgical safety checklist being hyped? BMJ 2019;366:14700..

13 Kwan JL, Lo L, Ferguson J, et al. Computerised clinical decision support systems and absolute improvements in care: meta-analysis of controlled clinical trials. $B M J$ 2020;370:m3216.

14 Thaler RH, Sunstein CR. Nudge: improving decisions about health, wealth, and happiness. New Haven: Yale University Press, 2008.

15 Sunstein C, Audits S. Behavioural public policy, 2020. Available: https://www.cambridge.org/core/journals/ behavioural-public-policy/article/sludge-audits/12A7E338984C E8807CC1E078EC4F13A7

16 Hill A. Why Nudges Coerce: experimental evidence on the architecture of regulation. Sci Eng Ethics 2018;24:1279-95.

17 Thaler R. What's next for nudging and choice architecture? Organ Behav Hum Decis Process 2020. doi:10.1016/j. obhdp.2020.04.003. [Epub ahead of print: 22 Apr 2020].

18 Hallsworth M, Halpern D. EAST: four simple ways to apply behavioural insights. London, England: the behavioural insights team, 2014. Available: https:/www.bi.team/wpcontent/uploads/2015/07/BIT-Publication-EAST_FA_WEB.pdf

19 Pettigrew M, Maani N, Pettigrew L, et al. Dark nudges and sludge in big alcohol: behavioral economics, cognitive biases, and alcohol industry corporate social responsibility. Milbank Q. In Press 2000. 